\title{
Patient-Centered Pain Management Communication from the Patient Perspective
}

\author{
Marie C. Haverfield, $P h D^{1,2}$, Karleen Giannitrapani, $P h D^{1,2}$, Christine Timko, $P h D^{1,2}$, \\ and Karl Lorenz, MD ${ }^{1,2,3}$
}

${ }^{1}$ Veteran Affairs Palo Alto Health Care System, Center for Innovation to Implementation (Ci2i), California, USA; ${ }^{2}$ Stanford University School of Medicine, California, USA; ${ }^{3}$ RAND Corporation, California, USA.

\begin{abstract}
BACKGROUND: Pain management discussions between patient and provider can be stressful to navigate and greatly impact the care received. Because of the complexity, emotional color, and sensitivity of pain management, such discussions require a high degree of skill.
\end{abstract}

OBJECTIVE: To identify patients' perspectives of patientcentered care communication within the context of pain management discussions.

DESIGN: We conducted semi-structured interviews (25$65 \mathrm{~min}$ ) with patients regarding their experiences with pain assessment and management.

Participants: 36 patients (29 males, 7 females), from 3 Veteran Affairs healthcare locations. Participant age ranged from 28 to 94 with pain intensity ranging from 0 to 10 , based on the "pain now" numeric rating scale report gathered at the time of the interview.

Approach: Interview transcript analysis was conducted using the constant comparison method to produce mutually agreed upon themes.

KEY RESULTS: Elements of patient-centered care communication described by participants include judgment, openness, listening, trust, preferences, solution-oriented, customization, and longevity. Patients perceive provider reciprocation in openness and trust as drivers of the patient-provider relationship, thereby enhancing positive, associated themes. CONCLUSIONS: Findings highlight the importance of the patient-provider relationship in patient-centered care and offer patient-centered care communication tools for practitioners to utilize, such as solution-oriented messages and communicating trust, especially when interacting with patients about pain.

KEY WORDS: pain; patient participation; doctor-patient communication; relationships; qualitative research.

J Gen Intern Med 33(8):1374-80

DOI: $10.1007 / \mathrm{s} 11606-018-4490-y$

(c) Society of General Internal Medicine (This is a U.S. Government work and not under copyright protection in the US; foreign copyright protection may apply) 2018

\section{BACKGROUND}

Pain management, which affects approximately 25.3 million adults nationwide, ${ }^{1}$ can be a difficult and frustrating experi-

Received December 13, 2017

Revised April 17, 2018

Accepted April 27, 2018

Published online May 29, 2018 experience. As a result of exposure to violence and social disadvantages, Veterans may have a heightened experience of pain. ${ }^{2}$ Medical providers are often patients' primary resource to address pain concerns and access pain solutions. However, patients and providers frequently hold differing points-of-view, making discussions about pain a challenge. ${ }^{3}$ While providers report difficulty in prescribing opioids and trusting patients' pain reports, patients may feel providers are not listening to concerns and overprescribe medication. ${ }^{4,5}$ Although this disconnect is well documented, less is known about the communicative features of discussions that patients perceive as helpful or hurtful to good pain care.

Patient-centered care, broadly defined as providers' attentiveness towards patient care preferences and needs, ${ }^{6}$ serves as a framework for examining communication. Patient-centered care communication underscores engagement of patients in decision-making, consideration of patients' emotions, keeping patients informed, and motivating patient self-management. ${ }^{6}$, ${ }^{7}$ These approaches promote better patient-provider communication and improve patient outcomes including medication adherence and satisfaction. ${ }^{8}$ Less understood are the components of communication behavior that facilitate or hinder effective patient-centered care. ${ }^{7,9}$ Patients' preferences for communication are key to understanding how providers might improve interactions. Furthermore, due to Veterans' potential for experiencing pain, they may provide a unique view of what patient-centered care communication about pain entails.

We interviewed Veteran patients to examine how they perceive patient-centered care communication during discussions with their providers about pain management. The purpose was to enrich our understandings of patient-centered care perspectives and offer insights for practitioners on communicative approaches to high-quality pain management.

\section{METHODS}

We conducted patient interviews as part of the Effective Screening for Pain (ESP) study (2012-2017), ${ }^{10}$ approved by the VA Central IRB. We consented a convenience sample $(N=36)$ of Veterans in five primary care clinics (four general clinics and one women's clinic in urban and rural locations), from three VA health care systems in California, Oregon, and 
Minneapolis. Participants were military Veterans waiting to see a provider for a visit where their vital signs and pain intensity would be documented. During recruitment, we asked Veterans if they would be willing to participate in phone interviews about pain care. Patients were asked to consider participating only if they had a working phone, and their hearing was adequate to complete a phone interview. Interview participants received a $\$ 30$ voucher for the VA canteen, a market that sells snacks and attire.

A semi-structured interview guide elucidated patient perceptions of pain screening and assessment (e.g., risks, benefits), and pain management and follow-up (e.g., care process, team involved, coordination). Patients were also asked their current pain intensity on a numeric rating scale (NRS) (e.g., what is your "pain now" on a scale of 0-10 with 0 being no pain and 10 being the worst pain imaginable). At the interview, $45 \%$ of respondents reported pain at 4 or above $(M=3.3) .{ }^{11}$ To preserve confidentiality, participants were not asked to explicitly disclose age and gender information. General sample demographic information was collected as part of a larger ESP study; therefore demographic information is not linked to specific transcripts. Interview questions about team communication prompted patient reflections about patient-centeredness. A specific probe about patent-centeredness was added after the first nine interviews.

To encourage patients to share their experiences and discuss sensitive issues, interviewers emphasized the anonymity of responses, that there were no right or wrong answers, and that answers would not be shared with providers. Although some patients identified as having no pain, all participants were able to reflect on previous discussions of pain with a provider. Data therefore reflect patients' perceptions across the pain severity spectrum. Interviews were audio recorded (with consent) and professionally transcribed (omitting identifying information), and transcripts were reviewed for accuracy.

Two investigators developed and iterated a code list via an initial coding of five transcripts. Next, the high-level code "patient-centeredness" was applied to all transcripts; this encompassed all references to patient-centered care communication such as being comfortable discussing pain with a provider, listening, and mentions of a relationship. Investigators $(\mathrm{MH}$ and $\mathrm{KG})$ then evaluated all examples relating to patient-centeredness and noted their general focus on communication between patient and provider. Using the constant comparison method, two investigators produced eight mutually agreed upon themes to describe patient-centered care communication components from patients' perspectives. ${ }^{12}$ The final list of emergent themes was then systematically applied to every mention of patient-centeredness. Secondary coders reviewed each transcript for inconsistencies. Team meetings fostered consensus for code development and resolutions for coding discrepancies. Analyses used qualitative analytic software ATLAS.ti. ${ }^{13}$

\section{RESULTS}

Thirty-six completed interviews included 29 men and 7 women. Interviews occurred between January and March of 2017 and lasted approximately $1 \mathrm{~h}$ (range 27-75 min). Patients ranged in age from 28 to 94 and had pain ranging from 0 to 10 on the NRS scale.

Eight themes of patient-centered care communication emerged (see Table 1). We describe each theme and provide example quotes with participant pain severity reports. Though all themes are based on patient perspectives, patient comments elucidated both patient and provider contributions to successful patient-centered care communication, reflecting a mutual contribution that works to foster a perceived patient-provider relationship.

\section{Theme 1: Judgment}

Patients appreciated when a provider avoided judgments during discussions of pain. When perceiving no judgment from providers, patients felt more comfortable interacting with the provider, noting that the visit felt more like a conversation between friends rather than a clinical discussion of pain, which could be beneficial for patient disclosure of health information:

I felt that she just started where I'm at...I never felt judged...I think there's a level of respect the way we manage a conversation between two individuals. (pain severity 3 )

Patients' concerns pertaining to provider judgment included being judged as weak due to reports of pain and being stigmatized as having an addiction to pain medication based on medication use or requests for pain medication. There was also concern of being labeled a complainer, by constantly noting instances of pain with the provider, which may inhibit effective pain management:

Then I went to a few doctors that don't even believe in chronic pain or fibromyalgia, you're just bellyaching...so I'm at the point now I don't even really talk about it that much. (pain severity 4)

\section{Theme 2: Openness}

Participants reported that it was their responsibility to be open with the provider. By being forthcoming, patients felt this would aid in effective pain management, facilitate the patient-provider relationship, and result in providers' reciprocation of openness:

I guess the more I can share with my provider, the more information I can give, the better able he or she is to make a decision based on my treatment. (pain severity 5) 
Table 1 Patient-Centered Care Communication Themes

\begin{tabular}{|c|c|c|}
\hline Theme & Definition & Quote \\
\hline Judgment & An open-minded assessment of pain experiences and needs & $\begin{array}{l}\text { "They've [provider] never shamed me. They've never said, 'Oh, it's } \\
\text { all in your head,' or anything like that. I've heard of people having } \\
\text { that problem." }\end{array}$ \\
\hline Openness & Willingness to share information with patient or provider & $\begin{array}{l}\text { "The number one person in charge of treatment is the individual } \\
\text { [patient]. If he doesn't bring up something which he feels is not } \\
\text { normal, how can you get the assistance needed and/or required." }\end{array}$ \\
\hline Listening & $\begin{array}{l}\text { Acknowledgement of information transferred through actions } \\
\text { that demonstrate understanding and consideration of the } \\
\text { message }\end{array}$ & $\begin{array}{l}\text { "Because they [provider] listen. They don't just like try to do their } \\
\text { job, but go beyond that...they feel empathy. And sometimes it's } \\
\text { very hard for us [patients]-or for me...to talk about my physical } \\
\text { and mental issues with family. It's nice to establish not only a } \\
\text { professional relationship but a personal relationship from someone } \\
\text { who knows more about how to deal with stuff, and I feel very } \\
\text { comfortable doing that." }\end{array}$ \\
\hline Trust & Belief in the intentions of the patient or provider & $\begin{array}{l}\text { "If the relationship isn't there and there's no trust between doctor } \\
\text { and patient, then you might as well not have doctor and patient." }\end{array}$ \\
\hline Preferences & $\begin{array}{l}\text { Agreed upon process of making a decision based on } \\
\text { individualized patient needs and preferences }\end{array}$ & $\begin{array}{l}\text { "For it to be a shared decision with your provider, your provider } \\
\text { should be saying...'Hey, I don't really know what else to try right } \\
\text { now. Let me go ahead and look into it and I'll get back to you.' The } \\
\text { ideal thing from there would have been for him to follow up and } \\
\text { say, 'Yep, I'm getting back with you. I think this would be } \\
\text { something to try,' and then from there make the decision } \\
\text { together...". }\end{array}$ \\
\hline $\begin{array}{l}\text { Solution- } \\
\text { oriented }\end{array}$ & $\begin{array}{l}\text { Provider commitment to addressing patient pain concerns } \\
\text { through multiple avenues of pain management strategies }\end{array}$ & $\begin{array}{l}\text { "It was wonderful. One of the things that I got out of it [support } \\
\text { group] was - and this is just very simple-I'm not the only one and } \\
\text { as bad as I think my pain is it's not an exclusive pain, and my } \\
\text { experiences are not exclusive experiences. I'm not a freak." }\end{array}$ \\
\hline Customization & $\begin{array}{l}\text { Provider consideration of physical and mental pain and } \\
\text { impact of pain on mental well-being }\end{array}$ & $\begin{array}{l}\text { "Yes, it should because he actually asked about function. He wants } \\
\text { to know whether I'm depressed about the pain. So there is...we talk } \\
\text { about that." }\end{array}$ \\
\hline Longevity & The history and expressed time spent with a provider & $\begin{array}{l}\text { "The biggest difference [in being comfortable] is having time with } \\
\text { that person [Provider], over time you build their trust and they get } \\
\text { to know you, they get to know your situation." }\end{array}$ \\
\hline
\end{tabular}

Similar to the barriers discussed above, patients reported that through conversations with their peers, many are often hesitant to openly discuss pain, thus presenting a barrier to openness:

Yeah. Some [patients] — not so much me, but some [patients] don't disclose very much. They're kind of quiet. (pain severity 5)

\section{Theme 3: Listening}

Though many patients used the term listening during their interviews, the important aspect of listening is the provider's listening behavior. Provider communication behaviors that contributed to perceptions of listening included acting on the pain information that was given, sharing additional information, asking follow-up questions, and taking the time to ensure an accurate understanding of the patient's experience with pain:

I guess feeling, with my specific doctor now, that he is more understanding... and more willing to listen. I've had some doctors that no matter, just like I said, have treated me like a drug addict, just because I was asking for pain medication with a legitimate reason and were reluctant to prescribe it at all. So with my current primary care physician, I guess just that he's been more willing to listen and discuss everything in depth. (pain severity 5 )
Patients identified barriers to providers' listening that included their own hesitations to disclose information, provider availability, and general lack of provider willingness to openly discuss patients' pain experiences and options:

...To actually talk about the pain, it's almost nonexistent, except for that little one to ten scale that you get before you even see the doctor. When I talk about my pain to the doctors, I really feel...this is just my personal perception, that their ears and eyes glaze over a little bit, it's like a language that they don't understand, in a sense. So I've learned not to talk about my pain with my doctors. (pain severity 4 )

\section{Theme 4: Trust}

Trust was stressed repeatedly throughout patient reflections of patient-centered care communication. Patients felt trust was crucial to discussions of pain and adherence to providers' pain management recommendations. A sense of having a relationship with a provider facilitated trust and perceived mutual trust:

She [provider] always asks me if I'm going to be good and if there's anything that I want to bring up before I leave or at the visit...I can't really speak on her behalf, but I think we have that two-way trust going on. (pain severity 3 ) 
Patients noted that if trust was not present in the interaction, by either the patient or provider, then there was no real relationship. Therefore, a lack of trust may act as a major barrier to the experience of having a relationship and receiving effective pain care:

"I don't fully trust the doctor's decision. Most of the time...before going to see the doctor, I've done my own research, as far as different options...Sometimes the doctors have disagreed with some of my different options, and I've had one doctor who clearly didn't want to hear my options. That's okay, but still this is what I researched, this is what I've heard, this is what I read, now where can we find a happy medium." (pain severity 1)

\section{Theme 5: Preferences}

Though some patients preferred to have their provider make all pain management decisions, many expected and appreciated a dialog about pain management options. In addition, patients regarded providers' expressions of shared concern as enhancing their partnership and decision-making:

He's very insightful and he lets me know he's on my side. He's not trying to dictate to me. He's there to help me to get through this period of time when I'm in great pain. And he's sort of my partner in a way. (pain severity 5)

Patients also identified barriers that inhibit their ability to engage in decision-making with their provider. Barriers related to the theme of openness and listening but reflected poor communication and listening behaviors, detracting from patient preferences. The greatest barrier to decision-making was when providers who previously had included patients in decision-making abruptly stopped. In turn, patients perceived a lack of respect for their own role in their health management:

We did Flexeril. We did tramadol. We did methocarbamol, which is Robaxin. And we did Celebrex. We did a couple others that have antidepressant properties to them. And then after that, it seemed like they were getting just as frustrated as I was about the fact that nothing seemed to be working. So then the decision was made without consulting me that we're just going to go ahead and switch... (pain severity 7 to 8 )

\section{Theme 6: Solution-Oriented}

Providers perceived as being solution-oriented presented patients with multiple avenues for managing pain that were customized to the needs and wants of the individual patient. This theme is different from preferences in that it focuses on the proactive contributions of the provider (and patient) in managing patient pain. In doing so, patients felt that providers were invested in them as a person, as well as the patientprovider relationship, and were committed to improving experiences of pain:

I would just say like an open, frank discussion of what the options are and give multiple options and what the benefits are for one treatment versus another. Rather than just being like, oh, here, I can write you a prescription for that; getting a little more into it...hey, we've got these other options available, have you thought of this type of thing. (pain severity 5)

In many of the references to a solution-oriented approach to pain management, patients expressed concern that providers may be quick to prescribe pain medication in an attempt to appease them, poorly reflecting a provider's commitment to their health:

I would like him to come to the table with some solutions...YYou know, there's this new opportunity out here. I would like to know if you're interested in this.' Come to me with a solution...I say, "I'm broken" and they fix that immediate symptom, but we don't really have a conversation about trends. (pain severity 1 to 2 )

\section{Theme 7: Customization}

Patients regularly noted that they appreciated providers who go beyond the physical pain and consider mental health. Patients reported that severe chronic pain could exacerbate or lead to feelings of depression. Therefore, it was important for providers to understand the patient's pain needs on multiple levels and open up a dialog to explore this with patients:

Well, I mean, but that's part of the next logical question. But on the pain form it says, "How much pain are you in today?" And the idea is that it's physical only. And one of the things like with a lot of Veterans, you know, there's a lot of... Veteran suicide rates are elevated. Right? Depression elevated. So sometimes the pain and the wounds aren't just on the outside, but folks are really hurting on the inside. (pain severity 1 to 2 )

Patients also identified barriers to the consideration of physical pain and corresponding mental health. Barriers included the unavailability of providers and the systemic pressures that inhibit providers from discussing and identifying pain concerns to customize care:

They're [providers] being pressed...to basically push the cattle through the processing time. They're getting pushback from their supervision to seeing more patients per day. But just because you're seeing more 
patients and it looks good on paper doesn't mean you're getting quality care. (pain severity 7 to 8 )

\section{Theme 8: Longevity}

Longevity is a unique theme because it is both a product of and a contributor to effective patient-centered care communication. As such, longevity is not a communication theme per se but rather a culmination of the themes described. Patients often noted the importance of time and history with their provider as the reason for openness and trust, but the existence of openness and trust also supports an ongoing relationship with the provider:

So, I've noticed that if you work with the doctor for six months or so, things start rolling a little smoother...I felt like, okay, I need to settle down and stop moving, because if I don't, I'm not going to get the treatment I need because no one will listen to me until they've known me for a while. (pain severity 4)

On the other hand, some patients identified provider turnover and changing of providers as a deterrent to longevity and effective pain management:

It's hard for us [patient] to give that trust. But we also have to understand that their [provider] role is to help us. And it was hard for me to overcome it [giving trust]...if there's going to be another provider assigned to me... if my provider needs to move to a different job or responsibility and I need to speak with a new one, that may be, again, a new process to build it [trust]. (pain severity 3)

\section{DISCUSSION}

Though each of the themes identified in the data is distinct, many patients reflected on the themes collectively. We conceptualize the intersection of themes in three ways. First, patient-centered care communication about pain benefits from establishing a patient-provider relationship. Second, reciprocation is essential to relationship development. Third, continued commitment to the relationship, via reciprocal exchanges, contributes to perceptions of productive ongoing care with that provider.

Four of the themes salient to patients were openness, nonjudgment, listening, and trust. These terms are frequently referenced in the patient-centered, and relationship-centered, care literature emphasizing the important role they play in the patient experience. ${ }^{6,14-17}$ However, the literature appears to fall short of how these elements contribute to patient-centered care communication. Self-disclosure, or the sharing of personal information to another, is at the foundation of relationship development. ${ }^{18}$ Therefore, a lack of self-disclosure or openness would make it difficult for a provider to gather information about a patient or understand the individual pain experience and needs of a patient, potentially affecting both the success of future interactions and the ability to manage patients' pain.

Patients are more likely to self-disclose pain management experiences when the provider is perceived as nonjudgmental, and there is confirmation that the provider is listening. In the absence of judgment, patients disclosed more information. ${ }^{19,} 20$ Patients perceived that providers trusted them by not passing judgment when patients expressed pain concerns and avoided overt skepticism when responding to patient medication requests. Trustworthy behaviors by providers reinforced patients' willingness to trust and were manifested by the act of supportive listening, which encompassed validation of patients' pain experiences. ${ }^{21}$ Listening in this sense is effortful and demonstrates the commitment providers have not just to the conversation and health condition but also to their relationship with the patient. Supportive listening may facilitate a clearer understanding of patient pain experiences, which then aids patients and providers to collaboratively reach a similar goal of managing pain. This pattern of behaviors and the resulting trust is necessary for both patients and providers to successfully navigate patients' pain and build relationship quality.

The patient-provider exchange may be paramount to the patient-centered care model. Previous research highlights the significance of this reciprocal effect finding that patients' active participation in a health care visit increases physicians' patient-centered care communication. ${ }^{22,23}$ Though in the context of patient-provider relationships it is unlikely that a provider will disclose personal information about himself or herself, there appear to be other forms of expressing mutuality. Reciprocation in this relational context may be reflected in demonstrations of listening or expressions of trust towards the patient that encourage trust towards the provider. The important role that reciprocation plays in patient-centered care is also evident in the themes of preferences, being solution-oriented, and customization. Expression of mutuality facilitates shared decision-making, customization of care, and affords a more holistic view of patient needs which may allow providers to respond more sensitively to pain concerns. ${ }^{24}$ Thus, customization of pain care may be easier to accomplish when patient and providers actively reciprocate features of communication such as openness and trust.

Perhaps the greatest take-away from the identified themes is that they manifest through a process of interactions. It is unlikely that a patient will experience trust after the first interaction with a provider or that expectations of both provider and patient are declared after one visit. Multiple interactions over time generate a constructive level of intimacy between patients and providers. This reciprocal exchange is particularly relevant to pain management because pain is so complex. Associated issues such as prior abuse or self-harm may drive the pain experience, requiring more time to address and disclose pain concerns. Patients' references to longevity connote the goal of a patient-provider relationship and also 
underscore the value of long-term relationships as a context for successful pain management. Though more research is necessary to understand the influence and outcome of longevity, our findings assist in the maintenance of the patientprovider relationship. Examining other relational constructs such as uncertainty and conflict would be important next steps in this avenue of research. In sum, the sharing of information and reciprocation facilitates ongoing interaction and promotes better health care.

Regarding limitations, our sample includes only Veterans. That said, we believe our findings are relevant to the broader patient pain population. Second, our sample is predominantly male; however, participants' responses consistently echoed one another. Third, because the interview questions did not specifically inquire about features of communication (verbal and nonverbal), there are likely additional communication elements such as touch and uncertainty to consider. Similarly, communication expectations may differ depending on the role of the provider. Fourth, because we did not gather information about the specific types of pain participants' experienced, only that they had experienced pain in general, we are unable to examine how these themes may differ among types or chronologies of pain. Our study was robust, however, in identifying themes consistent across pain types and pain of variable severity and chronicity.

Findings elucidate features of patient-centered care communication, and promote a transactional, rather than unidirectional (provider to patient) understanding of patient-centered care communication. ${ }^{6}$ Results from this study can assist providers in approaching their patient interactions, especially patients struggling with pain, by considering themes of patientcentered care communication that are most salient to patients. Inclusion of these communicative elements may make it easier to understand patient pain experience and expectations, identify patient emotions, and navigate difficult conversations to improve pain management.

Acknowledgements: The authors would like to thank Jesse Holliday for scheduling the Veteran phone interviews as well as Matthew McCaa, R. Thomas Day, Agnes Jenson, Derek Vang, and Holly Williams for recruiting the patients to the ESP study. We would also like to acknowledge the other investigators on the greater ESP project team including Steven Dobscha, Erin Krebs, Peter Glassman, Robert Kerns and Sangeeta Ahluwalia, whose intellectual contribution helped inform the development of this work. Finally, we would like to thank all the Veterans who agreed to participate in our interviews.

Corresponding Author: Marie C. Haverfield, $\mathrm{PhD}$; Stanford University School of Medicine, Palo Alto, California, USA (e-mail: mch83@stanford.edu).

Funding Data were collected as part of the Effective Screening for Pain (ESP) study part of the VA HSR\&D CREATE program 13-O2O (PI Lorenz). Dr. Haverfield was supported by VA Palo Alto Center for Innovation to Implementation HSR\&D postdoctoral fellowship. Analysis and Dr. Giannitrapani's effort was funded by a locally initiated project granted by the Center for Innovation to Implementation (Ci2i): LIP GIK0001134 (PI Giannitrapani). Dr. Timko's effort was supported by VA HSR\&D RCS OO-0O1.

\section{Compliance with Ethical Standards:}

Conflict of Interest: The authors declare that they have no conflict of interest.

\section{REFERENCES}

1. Nahin RL. Estimates of pain prevalence and severity in adults: United States, 2012. Journal of Pain. 2015; 16(8):769-780. https://doi.org/10. 1016/j.jpain.2015.05.002

2. Kerns, RD, Otis, J, Rosenberg, R, \& Reid, MC. Veterans' reports of pain and associations with ratings of health, health-risk behaviors, affective distress, and use of the healthcare system. Journal of rehabilitation research and development. 2003; 40:371-379.

3. Matthias, MS, Krebs, EE, Bergman, AA, Coffing, JM, \& Bair, MJ. Communicating about opioids for chronic pain: A qualitative study of patient attributions and the influence of the patient-physician relationship. European Journal of Pain. 2013; 18:835-843. https://doi.org/10. 1002/j.1532-2149.2013.00426.x

4. Matthias, MS, Bair, MJ, Nyland, KA, Huffman, MA, Stubbs, DL, Damush, TM, \& Kroenke, $\mathbf{K}$. Self-management support and communication from nurse care managers compared with primary care physicians: a focus group study of patients with chronic musculoskeletal pain. Pain Management Nursing. 2010; 11(1):26-34. https://doi.org/10.1016/ j.pmn.2008.12.003

5. Matthias, MS, Parpart, AL, Nyland, KA, Huffman, MA, Stubbs, DL Sargent, C, \& Bair, MJ. The patient-provider relationship in chronic pain care: providers' perspectives. Pain Medicine. 2010; 11 (11):1688-1697. https://doi.org/10.1111/j.1526-4637.2010.00980.x

6. McCormack, LA, Treiman, K, Rupert, D, Williams-Piehota, P, Nadler, $\mathbf{E}$, Arora, NK, ... Street, RL. Measuring patient-centered communication in cancer care: A literature review and the development of a systematic approach. Social Science \& Medicine. 2011; 72:1085-1095. https://doi. org/10.1016/j.socscimed.2011.01.020

7. Epstein, RM, Duberstein, PR, Fenton, JJ, Fiscella, K, Hoerger, M, Tancredi, DJ, ... Kaesberg, P. Effect of a patient-centered communication intervention on oncologist-patient communication, quality of life, and health care utilization in advanced cancer: the VOICE randomized clinical trial. JAMA oncology. 2017;3(1), 92-100.

8. Robinson, JH, Callister, LC, Berry, JA, \& Dearing, KA. Patient-centered care and adherence: Definitions and applications to improve outcomes. Journal of the American Association of Nurse Practitioners. 2008;20(12):600-607. https://doi.org/10.1111/j.1745-7599.2008. 00360.x

9. Rodin, G. Mackay, JA, Zimmerman, C, Mayer, C, Howell, D, Katz, M, Sussman, J, \& Brouwers, M. Clinician-patient communication: A systematic review. Support Care Cancer. 2009;17:627-644. https://doi. org/10.1007/s00520-009-0601-y

10. United States National Institutes of Health. Clinical Trial: Effective Screening for Pain Study (ESP) [cited 2017 July 01]. Available from: https://clinicaltrials.gov/ct2/show/NCT01816763.

11. Dobscha, SK, Morasco, BJ, Kovas, AE, Peters, DM, Hart, K, \& McFarland, BH. Short-term variability in outpatient pain intensity scores in a national sample of older Veterans with chronic pain. 2015;16(5):855865. https://doi.org/10.1111/pme. 12643

12. Glasser B, \& Strauss, A. The Discovery of Grounded Theory: Strategies for Qualitative Research Adline De Gruyter. New York. 1967.

13. ATLAS t.i. 7th ed. Software.

14. Beach, MC, \& Inui, T. Relationship-centered care. Journal of General Internal Medicine. 2006;21(S1). https://doi.org/10.1111/j.1525-1497. 2006.00302.x

15. Sabee, CM, Koenig, CJ, Wingard, L, Foster, J, Chivers, N, Olsher, D, \& Vandergriff, I. The process of interactional sensitivity coding in health care: conceptually and operationally defining patient-centered communication. Journal of health communication. 2015;20(7):773-782. https:// doi.org/10.1080/10810730.2015.1018567

16. Tickle-Degnen, L, \& Rosenthal, R. Nonverbal aspects of therapeutic rapport. Application of nonverbal behavior theories and research. 1992;143-164.

17. Roter, D. The enduring and evolving nature of the patient-physician relationship. Patient education and counseling. 2000;39(1):5-15. https://doi.org/10.1016/S0738-3991(99)00086-5

18. Greene, K, Derlega, VJ, \& Mathews, A. Self-disclosure in personal relationships. The Cambridge handbook of personal relationships. 2006;409-427. https://doi.org/10.1017/CBO9780511606632.023 
19. Baldacchino, A, Gilchrist, G, Fleming, R, \& Bannister, J. Guilty until proven innocent: A qualitative study of the management of chronic noncancer pain among patients with a history of substance abuse. Addictive behaviors. 2010;35(3):270-272. https://doi.org/10.1016/j.addbeh. 2009.10.008

20. Schäfer, G, Prkachin, KM, Kaseweter, KA, \& de C Williams, AC. Health care providers' judgments in chronic pain: the influence of gender and trustworthiness. Pain. 2016;157(8):1618-1625. https://doi.org/10. 1097/j.pain.0000000000000536

21. Bodie, GD, \& Jones, SM. The nature of supportive listening II: The role of verbal person centeredness and nonverbal immediacy. Western Journal of Communication. 2012;76(3):250-269. https://doi.org/10.1080/ 10570314.2011 .651255
22. Cegala, DJ, \& Post, DM. The impact of patients' participation on physicians' patient-centered communication. Patient education and counseling. 2009;77(2):202-208. https://doi.org/10.1016/j.pec.2009. 03.025

23. Street, RL, Gordon, H, \& Haidet, P. Physicians' communication and perceptions of patients: is it how they look, how they talk, or is it just the doctor? Social science \& medicine. 2007;65(3):586-598. https://doi.org/ 10.1016/j.socscimed.2007.03.036

24. Wade, DT, \& Halligan, PW. The biopsychosocial model of illness: a model whose time has come. Clinical rehabilitation. 2017; 31(8):995-1004. https://doi.org/10.1177/0269215517709890 